\title{
Preface to the Special Section of Selected Papers from the 28th Australasian Conference on Information Systems
}

\author{
Marta Indulska \\ UQ Business School, \\ The University of Queensland \\ m.indulska@business.uq.edu.au
}

\section{Virpi Kristiina Tuunainen}

School of Business

Aalto University

\section{Kai Riemer}

Discipline of Business Information Systems

The University of Sydney Business School

It is our privilege as the program co-chairs of the 28th Australasian Conference on Information Systems (ACIS) to have continued with the tradition of Australasian Journal of Information Systems (AJIS) Special Section focused on papers presented at ACIS. The ACIS conference is dedicated to providing an annual forum for local and international researchers to exchange ideas related to Information Systems topics. The conference, much like the AJIS journal, has a broad Information Systems scope, which is also reflected in the papers presented in this special section. The represented topics range from topical contributions focused on Information Systems security and also improving Information Systems related education, to methodologically related contributions providing guidance on measurement approaches, Design Science research, and a contribution providing guidance on adequate framing and argumentative writing of Information Systems research.

The papers we invited for potential publication in this special section underwent a rigorous and double-blind review process. Overall, we invited 7 papers and accepted 5 papers after 12 rounds of review. These 7 papers were selected on the basis of the views of the ACIS Program Committee and ACIS track chairs, from a total of 67 full-length papers accepted into the conference out of an original pool of 169 full-length submissions. All five papers included in this Special Section present an extension of the original ACIS paper publication.

We are thankful to the reviewers for their time and effort in shaping the selected papers, the authors for their expert revisions, and the AJIS editor for his assistance in creating this special section. We hope you will find this selection of papers of interest and enjoyable to read.

Sincerely, Marta, Virpi and Kai

AJIS Special Section Co-Editors

Copyright: @ 2019 Indulska, Tuunainen \& Riemer. This is an open-access article distributed under the terms of the Creative Commons Attribution-NonCommercial 3.0 Australia License, which permits non-commercial use, distribution, and reproduction in any medium, provided the original author and AJIS are credited. 


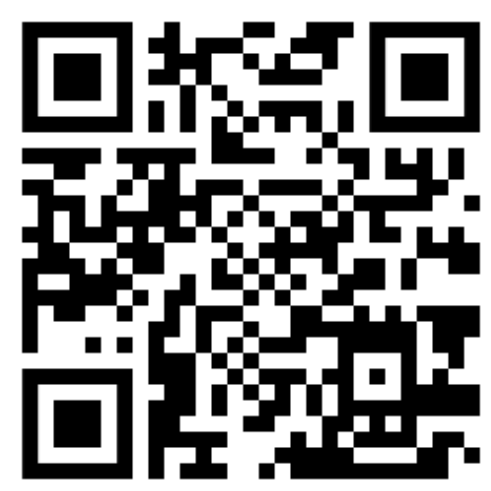

